\title{
Implementasi Bisnis Model Kanvas dalam Perancangan Manajemen Bisnis Aplikasi JASKOST
}

\author{
Wanda Fatricia ${ }^{1}$, Mokh. Adib Sultan ${ }^{2}$ \\ Program Studi Manajemen, Sekolah Pascasarjana, Universitas Pendidikan Indonesia, Bandung, Indonesia ${ }^{1}$ \\ Program Studi Manajemen, FPEB, Universitas Pendidikan Indonesia, Bandung, Indonesia²
}

\begin{abstract}
Business model concept at this moment considered as the alternative choice for entrepreneurs to design and develop a business. One of which frequently applied is Business Model Canvas. The purpose of this study is to implement the Business model canvas in designing the management of Jaskost-mobile based application. Jaskost is an application designed to meet the tenants' needs (anak kos). The method used is qualitative one with descriptive approach. The result shows that 9 elements of Business model canvas relate each other. Revenue streams is believed as the point of the Business model canvas elements which illustrates the income would be penetrated through the jaskost application. The implementation of business model canvas in designing the management of Jaskost-application in this study is as a representation of what must be done.
\end{abstract}

Keywords: Business Model Canvas; Entrepreneur; Jaskost

Abstrak. Konsep model bisnis hingga saat ini terus menjadi alternatif wirausaha dalam merancang dan mengenbangkan bisnisnya. Salah satu model bisnis yang sering digunakan adalah Bisnis Model Kanvas. Tujuan penelitian ini adalah menerapkan model bisnis kanvas dalam perancangan manajemen aplikasi JASKOST berbasis Mobile Application. Jaskost adalah sebuah aplikasi yang dirancang untuk memenuhi kebutuhan anak kost. Metode penelitian yang digunakan adalah metode kualitatif dengan pendekatan deskriptif. Hasil penelitian menunjukkan bahwa sembilan elemen model bisnis canvas memiliki hubungan satu sama lain. Revenue streams merupakan inti dari elemen model bisnis kanvas dimana elemen ini menggambarkan aliran pendapatan yang masuk keperusahaan melalui aplikasi Jaskost. Penerapan model bisnis kanvas dalam perancangan manajemen aplikasi Jaskost menjadi sebuah gambaran usaha yang akan dilakukan.

Kata kunci : Bisnis Model Kanvas, Jaskost, Kewirausahaan

Correspondence.wanda.fatricia@upi.edu, diebzoeltan@gmail.com

\section{PENDAHUluAN}

Kewirausahaan saat ini menjadi sebuah peluang usaha yang menarik diberbagai kalangan. Sangat banyak wirausaha yang bermunculan dengan berbagai ide kreatif dan inovasi terbaru. Mereka terus melukan inovasi produk, memperbarui sistem manajerial, serta berupaya mempertahankan posisinya dipasar, hingga berusaha mengikuti perkembangan digital saat ini. Upaya tersebut terus dilakukan, agar mereka mampu bersaing dipasar global, baik bisnis yang sudah berjalan maupun bisnis yang baru dibangun.
Perkembangan wirausaha di Indonesia saat ini menjadi tren yang tidak dapat ditinggalkan. Banyaknya wirausaha yang berhasil dapat membantu menaikkan suatu perekonomian Negara (Rahmanita \& Widyaningrum, 2018). Bahkan, Pemerintah Indonesia sangat mendukung para pelaku usaha yang terus meningkat. Saat ini, banyak wirausaha yang bermunculan dengan berbagai ide kreatif, baik dalam segi produk barang atau jasa, bahkan wirausaha yang mengambil peran dalam kategori Start-Up (Omsa, Ridwan, \& Jayadi, 2018). 
World Economic Forum yang menerbitkan "Global Competitiveness Report Index 20172018", menjelaskan bahwa Indonesia sedang bergerak maju menaikki lima tangga dari tahun 2017. Dimana Indonesia meningkatkan kinerjanya disemua aspek hingga menduduki posisi perekonomian ke-36 dari 137 negara yang ada didunia (Schwab, 2018). Posisi Indonesia di peringkat ini didorong oleh pasar yang besar dan terus meningkat. Meningkatkan keberhasilan usaha pada era saat ini, tidak akan lepas dari pemanfaatan teknologi yamg terus berkembang (Andulkar \& Berger, 2018). Tekonologi merupakan salah satu faktor terpenting yang mendorong produktivitas bisnis dalam beberapa tahun belakangan (Garza \& Kurfess, 2018). Kemajuan teknologi yang terus meningkat, membuat pelaku bisnis harus mampu mengikuti perkembangan zaman dan memanfaatkan teknologi dengan sebaik-baiknya diberbagai bidang.

Pertunbuhan Start-Up di Indonesia pada tahun 2016 menjadi lebih attraktif dan memberikan dampak positif kepada masyarakat (Daily Social, 2016). Hasil "Start-Up Report 2017" menunjukkan bahwa pada tahun 2017 sebanyak 230 Start-Up telah diluncurkan (Daily Social, 2017). Wirausaha di kategori Start-Up harus mampu mengelolah bisnisnya dengan sebuah model bisnis yang terarah (Metts, 2014) dan pintar memanfaatkan teknologi (Faller \& Feldmúller, 2015) agar bisnis tersebut diterima oleh masyarakat. Tidak dapat dihindari bahwa integrasi teknologi (Abramowicz, 2015) memiliki potensi revolusi cara bisnis dari perencanaan, pelaksanaan hinggga pengawasan (Garza \& Kurfess, 2018; Müller et al., 2018).

Begitu juga dengan Jaskost harus memiliki sebuah model bisnis dalam membangun bisnisnya. Jaskost (Jasa Kost) merupakan sebuah aplikasi berbasis Mobile Application yang dirancang khusus untuk memenuhi kebutuhan anak kost. Jaskost diangkat dari fenomena banyaknya anak kost yang merantau jauh dari keluarga. Anak kost pada umumnya memiliki kesibukkan tersendiri yang menyebabkan kebutuhan pribadi mereka tidak dapat dipenuhi ketika jauh dari keluarga. Selain itu, anak kost pada umumnya ingin segala proses simple dan cepat. Belum lagi, banyaknya kekurangan dari setiap individu anak kost yang menyebabkan kesulitan dalam memenuhi kebutuhan seharihari. Jaskost memiliki beberapa fittur didalamnya dengan fungsi-fungsi yang berbeda. Mulai dari jasa memesan makanan, jasa laundry, jasa transportasi, penyedia layanan jasa service hingga layanan jual beli barang anak kost yang sudah pernah dipakai maupun yang baru.

Sebuah model bisnis harus diterapkan dalam pengimplementasian Jaskost. Hal ini sangat perlu diterapkan pada tahap perencanaan bisnis untuk memberikan suatu gambaran kepada wirausaha dalam pelaksanaan, kontrol dan evaluasi bisnis Jaskost kedepan. Inovasi model bisnis yang terus berkembsng menjadi salah satu aspek penting yang harus diperhatikan oleh pelaku Start-Up. Model bisnis yang dikembangan secara teratur dan sistematis dapat menjadi bahan pertimbangan ketika pengambilan keputusan, pemgembangkan strategi bisnis kedepan serta menjadi gambaran solusi ketika adanya masalah dalam proses pelaksanaan.

Salah satu inovasi model bisnis yang berkembang saat ini dikenal dengan Model Bisnis Kanvas (Chesbrough, 2007; Hedman \& Kalling, 2003; Maglio \& Spohrer, 2013; Shafer, Smith, \& Linder, 2005; Tikkanen, 2005; Voelpel, et. al., 2005; Zott, 2007: Giesen, et. al., 2013). Implementasi model bisnis kanvas terus terus dilakukan dalam upaya perbaikkan model bisnis yang berjalan (Al-debei \& Avison, 2010; Nenonen \& Storbacka, 2010; Smedlund, 2012; Kindstrom \& Kowalkowski, 2014; Ojasalo, 2018). Konsep model bisnis kanvas memiliki kekuatan praktis yang sangat besar (Magretta, 2002), dan akan menjadi pertimbangan manajer dalam mengambil keputusan yang telah diprediksi ataupun tidak (Mcgrath, 2010).

\section{KERANGKA PENELITIAN \& HIPOTESIS}

Kewirausahaan merupakan kemampuan kreatif dan inovatif yang dijadikan dasar untuk menciptakan sesuatu yang baru dan berbeda (create new and different) (Suryana \& Bayu, 2011:45). Konsep kewirausahaan yang meluas diberbagi bidang, termasuk dalam teknologi menjadi salah satu hal yaang tidak dapat 
dihindari bahwa integrasi teknologi (Abramowicz, 2015) memiliki potensi perubahan cara bisnis dari perencanaan, pelaksanaan hinggga pengawasan (Muller et al., 2018).

Jaskost sebagai salah satu Start-Up yang akan mengembangkan bisnisnya harus memiliki sebuah model bisnis untuk menciptakan suatu strategi perusahaan yang layak, memiliki keunggulan dan tearah (Metts, 2014). Salah satu inovasi model bisnis adalah model bisnis kanvas (Osterwalder \& Pigneur 2010).

Model bisnis kanvas mampu memetakan segala strategi perusahaan, sehingga memudahkan pengusaha untuk mengambil keputusan terkait dengan pengembangan usaha. Konsep model bisnis kanvas memiliki kekuatan praktis yang sangat besar dan akan menjadi pertimbangan manajer dalam mengambil keputusan yang telah diprediksi ataupun tidak (Mcgrath, 2010).

Model bisnis kanvas ini memberikan sajian model bisnis dengan pemetaan sembilan elemen didalamnya, yaitu : customer segments, value propositions, channels, customer relationships, revenue streams, key resources, key activities, key partnership, dan cost structure (Osterwalder \& Pigneur 2010).

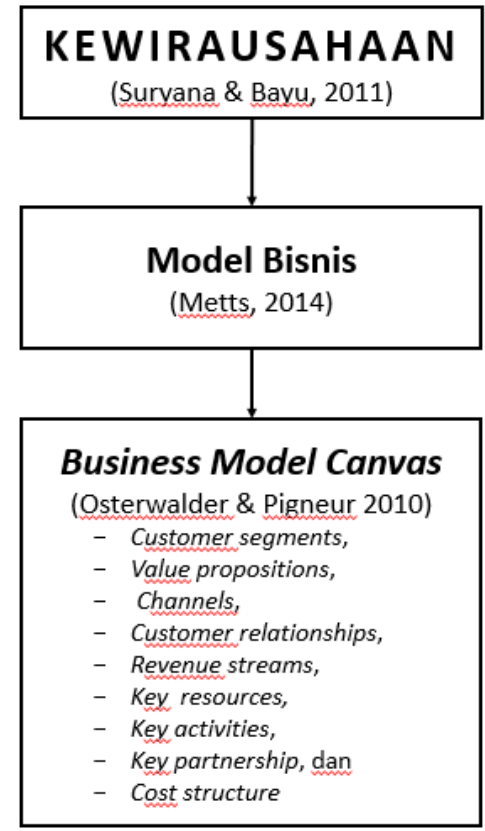

Gambar 1. Kerangka Penelitian

\section{METODE PENELITIAN}

Dalam penelitian ini, metode yang digunakan adalah metode kualitatif dengan jenis deskriptif. Pengumpulan data menggunakan sumber primer dan sumber sekunder. Teknik penentuan informan menggunakan metode purposive sampling, yaitu teknik penentuan informan berdasarkan pertimbangan subyektif peneliti (Sugiyono, 2012). Pada tahap analisis, keseluruhan data di analisa dari setiap elemen dalam model bisnis kanvas dan hubungannya antar setiap elemen. Terakhir, dokumentasi perangcangan aplikasi Jaskost pada model bisnis kanvas.

\section{HASIL DAN PEMBAHASAN}

Perancangan aplikasi Jaskost (Jasa Kost) berbasis Mobile Application adalah sebuah aplikasi marketplace yang dirancang untuk semua kalangan pada umumnya dan khusus untuk anak kost. Jaskost memberikan bantuan untuk memfasilitasi kebutuhan anak kost saat jauh dari rumah. Mulai dari adanya layanan laudry, pesan antar makanan, transportasi ojek online, jasa service seperti $t v$, dispenser, rice cooker hingga adanya layanan jual beli barang dari anak kost untuk anak kost itu sendiri maupun masyarakat luas. Barang yang dijual bisa berupa barang bekas ataupun barang baru.

Fokus utama perkembangan aplikasi Jaskost saat ini terletak pada fittur jasa service dan jual beli barang bekas anak kost. Hal ini berfokus karena peneliti telah melakukan survey kepada bebrapa anak kost tentang kebutuhan mereka yang belum terpenuhi. Kesulitan menemukan layanan jasa service membuat terkadang banyaknya barang rusak menjadi tidak bemanfaat dan terbuang begitu saja. Padahal kerusakkan pada barang tersebut tidak terlalu berat. Hanya saja, kekurangan keahlian pada individu anak kost mengakibatkan anak kost tidak mampu memperbaiki kerusakkan tersebut.

Namun, bukan hanya fittur jasa service dan jual beli barang bekas yang akan dikembangkan. Semua fittur tetap akan dikembangan dengan fungsinya masing-masing. Hanya saja, fittur jasa service dan jual beli barang anak kost menjadi icon dalam aplikasi jaskost itu sendiri. Adanya aplikasi Jaskost ditengah-tengah masyarakat, khususnya untuk anak kost yang dapat 
digolongan dalam kalangan mahasiswa diharapakan dapat menjadi solusi dalam beberapa permasalahan yang dihadapi anak kost.

Bisnis jasa seperti ini sebenarnya telah banyak digeluti oleh para pelaku bisnis. Namun, peneliti telah melakukan survey keberapa aplikasi yang ada, bahwa fittur utama dalam bisnis layanan untuk anak kost berfokus pada pencarian rumah atau kost-kostsan untuk anak kost. Tidak ada sebuah marketplace atau aplikasi khusus yang memberikan layanan jasa untuk kebutuhan anak kost. Contohnnya KostHERO, Cari-Kos.com, Mami Kost, InfoKost dan lainnya.

\section{ANALISIS PESAING}

Amalisis pesaing dalam membangun sebuah bisnis baru sangat penting. Hal ini berguna untuk melihat bagaimana posisi bisnis diletakkan, misalnya : dalam posisi pasar, Jaskost sebagai layanan bisnis jasa mentargetkan diri sebagai perusahaan yang bersaing dengan perusahaan jasa lainnya dengan fokus untuk memenuhi kebutuhan anak kost. Segmentasi Jaskost fokus kepada mahasiswa/mahasiswi yang sedang menempuh pendidikan maupun bekerja jauh dari keluarga. Walaupun pada umunya, semua kalangan dapat menggunakan layanan jasa dari aplikasi Jaskost.

Dikekuatan pasar, Jaskost mampu bekerja sama dengan pelaku UKM yang berada dekat dengan lingkungan anak kost. Hal ini dikarenakan Jaskost memiliki segmentasi khusus yatu anak kost dengan kalangan mahasiswa/mahasiswi yang ada diseluruh Indonesia. Banyak sekali UKM sekitaran Univeristas yang sebenernya memiliki potensi bagus dalam perkembangan usahanya. Namun, bisnis yang dianggap begitu kecil ini sering kali dilupakan. Tidak hanya itu, Jaskost juga mampu bekerjasama langsung dengan masyarakat sekitar untuk menjadi partner dalam memenuhi kebutuhan anak kost.

Dilingkungan anak kost sendiri sebenarnya banyak sekali terdapat masyarakat yang memiliki potensi lebih, hanya saja mereka belum disatukan dalam sebuah aplikasi yang mampu memperkenalkan potensi tersebut kepada semua kalangan. Dalam beberapa tahun kedepan Jaskost memiliki rencana strategi untuk mengembangkan bisnisnya dengan memperluas segmen pasar dan terus menaikkan kulialitas layanan Jaskost baik dari dalam maupun luar perusahan Jaskost sendiri.

Kelemahan bisnis pelayanan jasa seperti ini tidak selalu dapat diawasi secara utuh oleh pemilik bisnis. Jika ada pelayanan yang kurang baik dari partners bisnis kepada konsumen ataupun pelanggan akan menjadi salah satu hal penting yang dapat mengurangi konsumen.

\section{Penerapan Bisnis Model Kanvas}

Model bisnis berperan untuk mengatur, mengkoordinasikan, menvisualisasikan, memahami, mengkomunikasikan dan mengintegrasikan logika bisnis secara keseluruhan (Osterwalder, 2004). Model bisnis yang dibuat harus cukup sederhana, logis, dapat diukur, komprehensif, dan bermakna secara operasional (Osterwalder, et. al, 2005). Adapun pemetaan bisnis model kanvas dalam sembilan elemennya, sebagai berikut :

\section{Customer Segment}

Mengembangkan sebuah produk harus disesuaikan dengan target segmentasi yang ditujuh oleh sebuah perusahaan, hal tersebut dilakukan agar produk dapat diterima dipasaran. Segmentasi pengguna aplikasi mobile Jaskost adalah pelajar, mahasiswa / mahasiwi, pekerja kantoran, masyarakat umum dan pengguna layanan transportasi.

\section{Value Proposition}

Value karena keuntungan dari Jaskost adalah memenuhi kebutuhan anak kost yang begitu banyak dan kemauan anak kost yang ingin semuanya lebih simple menjadi tantangan serta solusi adanya aplikasi Jaskost. Dengan aplikasi ini akan membantu mempermudah kebutuhan anak kost. Value Education disini maksudnya adalah nilai edukasi yang mampu diberikan oleh aplikasi Jaskost kepada pelanggan dan konsumen. Value Education dari Jaskost sendiri adalah memberikan kemandirian kepada anak-anak kost yang mau memulai usahanya dalam aktivitas keseharian anak kost. Jaskost juga akan memberikan tips-tips mengenai hidup simple ala anak kost.

\section{Channels}

Channel disini menggambarkan bagaimana perusahaan berkomunikasi dan menjangkau segmen pelanggannya (Osterwalder \& Pigneur 
2010). Dapat dikatakan bahwa saluran distribusi disini adalah proses atau bagaimana aplikasi Jaskost dapat diketahui, digunakan dan dimanfaatkan oleh pelanggan. Adapun elemen channel dalam Jaskost yang dimanfaatkan adalah aplikasi online lainnya, testimoni pengguna, iklan media cetak, iklan media elektronik dan iklan media sosial.

\section{Customer Relationships}

Sebuah bisnis baru harus diketahui oleh calon pelanggan, karena itu sangat perlu untuk menyuarakan bisnis tersebut. Customer relationships dapat dikatakan bagaimana cara perusahaan menentukan jenis hubungan kepada segmen pelanggan (Osterwalder \& Pigneur 2010) agar tercipta komunikasi yang baik. Untuk Jaskost sendiri, hubungan dengan pelanggan dijaga baik secara offline maupun online. Berbagai cara bisa dilakukan, yaitu dengan diskon dan promo yang menarik perhatian pelanggan, sehingga menciptakan komunikasi lebih baik dengan pelanggan, menyediakan e-mail newsletter serta aplikasi dengan beberapa Fitur yang membantu pelanggan dalam memenuhi kebutuhannya.

\section{Revenue Streams}

Elemen ini merupakan inti dari model bisnis (Osterwalder \& Pigneur 2010). Pada elemen ini menggambarkan bagaimana aliran pendapatan yang masuk ke perusahaan melalui aplikasi Jaskost. Aliran pendapatan dari aplikasi Jaskost, dari pengguna layanan aplikasi Jaskost, pembelian atribut Jaskost, keuntungan dari pembelian alat elektronik dan hasil Jual Beli barang kebutuhan anak kost.

\section{Key Resource}

Sumber daya disini mulai dari pengolahan bahan baku, penataan SDM, penataan proses operasional. Sumber daya merupakan aset terpenting yang diperlukan untuk membuat model bisnis berfungsi (Osterwalder \& Pigneur 2010). Key Resources Jaskost adaalah aplikasi WA, Google Maps dan Insfrastuktur Server.

\section{Key Activities}

Kegiatan utama dalam sebuah model bisnis saatlah penting. Hal ini akan menjadi fokus langkah dan persiapan kearah mana bisnis akan dikembangan. Melalui elemen ini akan digambarkan apa yang akan dilakukan perusahaan untuk membuat model bisnis yang dirancang bekerja, seperti produksi, pemecahan masalah, kegiatan platform dan jaringan yang digunakan (Osterwalder \& Pigneur 2010). Adapun kegiatan-kegiatan yang akan dilakukan Jaskost dalam mengembangkan bisnisnya agar efektif adalah menghubungan Driver dengan pelanggan, menghubungan penyedia layanan Jasa dengan pelanggan dan manajemen data pengguna.

\section{Key Partnership}

Kemitraan kunci disini merupakan jaringan pemasok dan mitra yang membuat model bisnis berfungsi (Osterwalder \& Pigneur 2010). Kemitraan mungkin merupakan aliansi strategis antara non-kompetitor dan juga pesaing, rekan kerja, pemasok dan semua yang terlibat untuk mengembangkan perusahaan. Partner-partner yang memungkinkan perusahaan dapat mewujudkan produk atau jasa aplikasi Jaskost adalah mitra pengemudi, supplier atribut, supplier kebutuhan elektonik dan penyedia Infratuktur server.

\section{Cost Structure}

Mengelolah biaya secara efisien akan membuat bisnis yang kita jalankan menjadi lebih hemat dan bisa meminimalkan resiko kerugian. Pada bagian struktur biaya ini menjelaskan semua biaya yang dikeluarkan untuk mengoperasikan model bisnis yang telah dirancang (Osterwalder \& Pigneur 2010). Cost Structure dari Jaskost adalah bagi hasil dengan mitra layanan Jasa dan pengemudi, gaji pengawai kantor, biaya aplikasi Google Maps, penyewaan infrastuktur server dan biaya permeliharaan dan perbaikkan system.

Hasil dari pembahasan dan pemetaan sembilan elemen model bisnis kanvas diatas, dapat digambarkan sebagai berikut: 


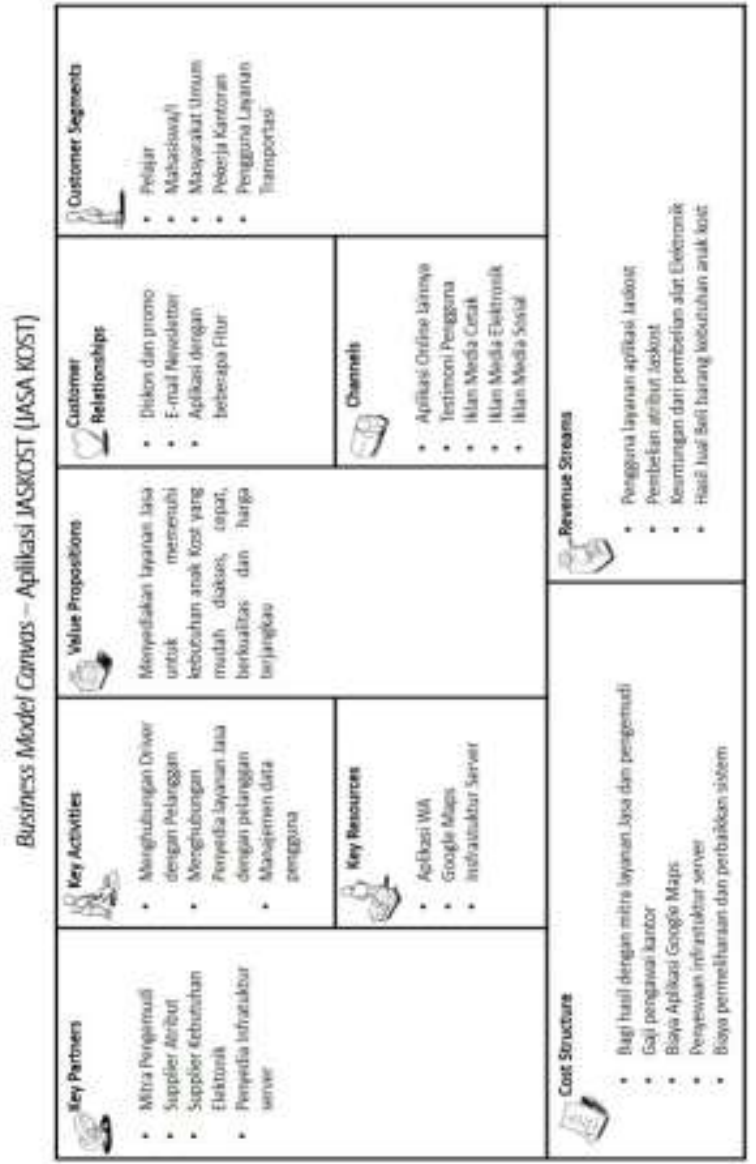

Gambar 2. Hasil Model Bisnis Kanvas Aplikasi Jaskost

\section{KESIMPULAN}

Bisnis model kanvas tidak hanya diperuntukkan untuk sebuah bisnis baru saja. Namun, pada bisnis yang telah berjalan juga dapat diimplementasikan model bisnis kanvas. Pemetaan sembilan elemen pada model bisnis kanvas sangat membantu dalam merangcang sebuah bisnis baru. Melalui rancangan model bisnis kanvas, perusahaan mampu melihat lingkungan dan sasaran dari perusahaan Jaskost secara detail.

Selain itu, rancangan model bisnis kanvas menjadi pertimbangan dalam pengambilan keputusan perusahaan serts menjadi alternatif perusahaan ketika ada masalah dan kendala. Semua elemen pada model bisnis kanvas berkaitan satu sama lain. Itu artinya, semua elemen harus berjalan dengan baik dan beriringan satu sama lain. Elemen reveneu stream menjadi inti dari model bisnis kanvas karena elemen ini menggambarkan bagaimana aliran pendapatan yang masuk ke perusahaan. Adanya pemetaan aliran pendapatan yang masuk keperusahaan, menjadi pertimbangan dalam perusahaan untuk mendeskripsikan kegiatankegiatan yang harus dilakukan oleh perusahaan dalam pelaksanaan bisnis.

\section{REKOMENDASI}

Implementasi model bisnis kanvas dalam manajemen aplikasi Jaskost sangat membantu memetakaan segmentasi dan strategi bisnis Jaskost yang akan dikembangkan. Penelitian ini menunjukan bahwa, setiap perusahaan harus memeiliki sebuah model bisnis dalam mengembangkan bisnisnya.

Pengembangan dari penelitian ini dapat dilakukan oleh peneliti lain dengan melihat bagaimana pemetaan bisnis model kanvas membawa pengaruh yang signifikan atau tidak pada aplikasi Jaskost dengan melihat kesuksesan bisnis yang dijalankan.

\section{DAFTAR PUSTAKA}

Abramowicz, W. (2015). Business Information Systems :18th International Conference, BIS 2015 Pozna??, Poland, June 24-26, 2015 Proceedings. Lecture Notes in Business Information Processing, 208(April). https://doi.org/10.1007/978-3-319-190273

Ahuett-Garza, H., \& Kurfess, T. (2018). A brief discussion on the trends of habilitating technologies for Industry 4.0 and Smart manufacturing. Manufacturing Letters. https://doi.org/10.1016/j.mfglet.2018.02.0 11

Al-debei, M. M., \& Avison, D. (2010). Developing a unified framework of the business model concept, 19(3), 359-376. https://doi.org/10.1057/ejis.2010.21

Andulkar, M., \& Berger, U. (2018). A multi- case study on Industry 4.0 for SME' $s$ in Brandenburg, Germany, 4544-4553.

Chesbrough, Hz. (2007). Business model innovation : it ' s not just about technology 
anymore, $\quad 35(6), \quad 12-17$. https://doi.org/10.1108/10878570710833 714

Daily Social. (2016). Indonesia's Tech Startup Report 2016. Jakarta.

Daily Social. (2017). Start-Up Report 2017. Jakarta.

Faller, C., \& Feldmúller, D. (2015). Industry 4.0 learning factory for regional SMEs. Procedia CIRP, 32(Clf), 88-91. https://doi.org/10.1016/j.procir.2015.02.1 17

Giesen, E., Berman, S. J., Bell, R., Blitz, A., Giesen, E., Berman, S. J., ... Blitz, A. (2013). Three ways to successfully innovate your business model.

https://doi.org/10.1108/10878570710833 732

Hedman, J., \& Kalling, T. (2003). The business model concept : theoretical underpinnings and empirical illustrations, (October 2002), 49-59.

https://doi.org/10.1057/palgrave.ejis.3000 446

Jukka Ojasalo, Katri Ojasalo, (2018). (2018). Service Logic Business Model Canvas. https://doi.org/10.1108/JRME-06-20160015

Kindström, D., Kowalkowski, C., \& Kindstro, D. (2014). Service innovation in productcentric firms : a multidimensional business model perspective. https://doi.org/10.1108/JBIM-08-20130165

Maglio, P. P., \& Spohrer, J. (2013). Industrial Marketing Management A service science perspective on business model innovation. Industrial Marketing Management. https://doi.org/10.1016/j.indmarman.2013 .05 .007

Mcgrath, R. G. (2010). Business Models: A Discovery Driven Approach. Long Range Planning, 43(2-3), 247-261. https://doi.org/10.1016/j.Irp.2009.07.005

Metts, G. A., Metts, G. A., Wayne, I. F., \& Wayne, F. (2014). Measuring the effectiveness of managerial action in SMEs An empirical analysis of management ' $s$ response to industry competitive forces. https://doi.org/10.1108/01409170710833
330

Müller, J. M., Buliga, O., \& Voigt, K. I. (2018). Fortune favors the prepared: How SMEs approach business model innovations in Industry 4.0. Technological Forecasting and Social Change, (December 2017), 0-1. https://doi.org/10.1016/j.techfore.2017.12 .019

Müller, J. M., Buliga, O., \& Voigt, K. I. (2018). Fortune favors the prepared: How SMEs approach business model innovations in Industry 4.0. Technological Forecasting and Social Change, (December 2017), 0-1. https://doi.org/10.1016/j.techfore.2017.12.0 19

Nenonen, S., \& Storbacka, K. (2010). International Journal of Quality and Service Sciences Business model design: conceptualizing networked value cocreation.

https://doi.org/10.1108/17566691011026 595

Omsa, S., Ridwan, M., \& Jayadi, M. (2018). The Effect of Strategic Management Practices on SME Performances in Makassar, Indonesia, 3(4), 71-80. https://doi.org/10.11648/j.ajtab.20170304 .12

Rahmanita, E., \& Widyaningrum, V. T. (2018). SME Worker Affective ( SWA ) index based on environmental ergonomics SME Worker Affective ( SWA ) index based on environmental ergonomics. https://doi.org/10.1088/1757899X/337/1/012037

Report, I., Schwab, K., \& Forum, W. E. (2018). The Global Competitiveness Report.

Shafer, S. M., Smith, H. J., \& Linder, J. C. (2005). The power of business models $B$. https://doi.org/10.1016/j.bushor.2004.10. 014

Smedlund, A. (2012). Value Cocreation in Service Platform Business Models Value Cocreation in Service Platform Business Models, (May 2015).

Suryana, Y., \& Bayu, K. (2011). Kewirausahaan. Pendekatan Karakteristik Wirausahawan Sukses (Kedua). Jakarta: Prenadamedia Group.

Tikkanen, H. (2005). Managerial cognition, action 
and the business model of the firm, 43(6),

789-809.

https://doi.org/10.1108/00251740510603

565

Voelpel, S., Leibold, M., Tekie, E., \& Krogh, G. V.

O. N. (2005). Escaping the Red Queen Effect

in Competitive Strategy: Sense-testing Business Models, 23(1), 37-49. https://doi.org/10.1016/j.emj.2004.12.008

Zott, C. (2007). Business Model Design and the Performance of Entrepreneurial Firms, 18(2), 181-199. https://doi.org/10.1287/orsc.1060.0232 